\title{
SOME CONSEQUENCES OF THE "ENGINEERING 2000 CRITERIA" ON LIBERAL EDUCATION
}

\author{
Lance Schachterle \\ Worcester Polytechnic Institute
}

In December 1995, the Engineering Accreditation Commission (EAC) of ABET promulgated a draft set of new criteria for engineering programs called "Engineering Criteria 2000." These draft criteria are intended for circulation within the engineering and professional communities for two full years (1995-97), with the final review and vote on adoption scheduled for 1 November 1997. If the new criteria are adopted, a three-year phased implementation period will follow in the academic years 1998-1999 to 2000-2001, during which institutions may select either the old or new criteria. If accepted in present or modified form, these "Engineering Criteria 2000" will replace existing ABET criteria, and will become the universal standard by which all engineering programs will be assessed from the year 2001 onwards.

These new criteria represent not only a very different methodology for assessing engineering education, but also disclose a change in fundamental philosophy of how accrediting is to be done. The new criteria resemble the methodology now used by the Regional Accreditation Commissions, accreditation with whom basically registers a college or university as a legitimate educational entity recognized by state and federal governments. For years, the regional accrediting societies have used a three-part structure in their campus assessments:

1. Asking the institution being reviewed to indicate its mission and goals, which must be what is advertised to the student customer base;

2. Reviewing the curriculum that has been designed to achieve those goals, making certain that there is a close relationship between the publicly stated goals and the curriculum purporting to embody those goals; and

3. Examining the ways in which the institution engages in continuous self-study so that institutional assessment of the outcomes of the curriculum (in terms of what students can-and cannot do) is related back to appropriate adjustments in the curriculum, creating a beneficial feedback loop between student outcomes and the curriculum that is supposed to nurture them.

Thus, instead of the conventional mode of accreditation in ABET (experienced by most faculty throughout their whole professional lifetimes) which laid out in increasing detail the courses students had to pass in order for a program to be accredited, the proposed new curriculum looks at what students can do rather than what students have taken. The new outcomes, eleven in number, assess both students' disciplinary competence and their capacity to perform their disciplinary competence within a social context. In so doing, the new ABET curricular recognizes the frequently reported requests from industry that entering programs need not only to prepare people who are technically competent but also can begin quickly, while on the job, to carry out professional tasks in an open-ended problem-solving environment. (Examples of such reports include the 1995 Rand Corporation report, the SME\&T testimony given to the National Science Foundation in October 1995 by American corporations, and the 1992 NSPE survey of what employers most want in new engineering graduates.) 
The new Criteria state that "engineering programs must demonstrate that their graduates have:

(a) an ability to apply knowledge of mathematics, science and engineering;

(b) an ability to design and conduct experiments, as well as to analyze and interpret data;

(c) an ability to design a system, component, or process to meet desired needs;

(d) an ability to function on multi-disciplinary teams;

(e) an ability to identify, formulate, and solve engineering problems;

(f) an understanding of professional and ethical responsibility;

(g) an ability to communicate effectively;

(h) the broad education necessary to understand the impact of engineering solutions in a global/societal context;

(i) a recognition of the need for and an ability to engage in life-long learning;

(j) a knowledge of contemporary issues; and

(k) an ability to use the techniques, skills and modern engineering tools necessary for engineering practice."

Many of the criteria in the second half of this list exemplify desirable student performance outcomes that are frequently associated with study in the humanities and social sciences. (It is worth noting that the $\mathrm{H} / \mathrm{SS}$-related outcomes are couched not in terms of "ability" but in distinctly vaguer terms, perhaps acknowledging greater difficulties in assessing non-technical outcomes--solving calculus problems vs. ethical problems.) At the same time, the current draft requirements remove the requirement that students must spend a half year of study in the humanities and social sciences. In their place is a statement that speaks of the merits of general education without tying the general education program to any specific block of time: ABET accreditable programs should have "a general education component that complements the technical content of the curriculum and is consistent with the program and institution objectives."

The challenge that the new program offers to liberal educators within the engineering curriculum is to define a mission (in conjunction with our colleagues in science, engineering, and mathematics) for each institution such that the outcomes we associate with liberal education (in this sense especially the humanities, arts, and social sciences) can be developed and achieved within the curriculum. Those engineering programs which look to the humanities and arts to achieve outcomes such as:

(f) an understanding of professional and ethical responsibility;

(g) an ability to communicate effectively;

(h) ...understanding the impact of engineering solutions in a global/societal context;

(i) recognizing the need for and an ability to engage in life-long learning;

(j) having a knowledge of contemporary issues

should be successful in working with the new requirements.

Those institutions who currently have, or who are developing, a mission for their graduates that encompasses such elements as working within societal contexts, working in teams, and communicating effectively should be well served by the new criteria. Indeed, the new criteria offer the opportunity for a much stronger synergy between humanities, social sciences, and the engineering curriculum than has existed in the past where the humanities/social science component has often been quite separate from the real mission of the institute.

On the other hand, it may also be possible that at some institutions, where traditionally the humanities and social science courses have been offered through a college within the university distant from (in more senses than one !) the engineering unit, may find it more difficult both to create an appropriate mission and to assess it. Such situations have often been accused of sub-optimal use of student time in programs outside their major, and may be problematic in terms of achieving a broad collegial sense of mission, curriculum, and assessable outcomes.

Let me conclude with some suggested strategies for those institutions where the Liberal 
Arts-Humanities/Social Science requirements do play a significant role in the mission of the engineering programs. Based on the experience of my own institution, WPI,--one of the first two institutions ABET invited to "try out" the "Engineering Criteria 2000,"--let me suggest some possible strategies.

1. Correlate the eleven Criteria ( $\mathrm{a}-\mathrm{j}$ above) with your existing degree requirements as well as your curriculum. A matrix approach of arranging your distribution requirements on one axis, and the new Criteria on the other, is an effective way of locating and displaying existing correlations.

2. Relate the results of the matrix exercise to your institutional, college or unit mission statement, and to your publicity aimed at recruiting students--especially in terms of statements you make about your graduates' abilities.

3. Consider having your students all begin a portfolio of their accomplishments, preferably from their initial campus orientation through graduation. Many of the elements of the portfolio would be the fairly conventional parts that one would expect any institution to provide, such as transcripts, copies of written material including quizzes, lab reports and term papers, and a professional looking CV.

Students should also look at their extra curricular activities and include any activities that involve them in teamwork and demonstrate leadership skills. Also, any kind of job experience, especially related to their major, would be an important part of the portfolio.

It would also be important for students to indicate any kinds of team-based, open-ended problem solving which they may have accomplished as part of their course work. Increasingly, these kinds of activities play a role in courses from the first year through to the senior year.

4. Use such a portfolio as the basis of an exit interview when students graduate, in which H/SS faculty may play an active role. Students could use an appropriate version of the matrix to match their degree requirements against the new ABET criteria, to make conscious to themselves and to articulate the ways in which their program in aggregate has addressed all of the new ABET criteria. It would be especially helpful to show how your program repeatedly develops desirable outcomes incrementally and on different levels.

Pursuing such suggested strategies should also enable H/SS to work with their colleagues in other disciplines to articulate appropriate missions for our disciplines. Hopefully such exercises will be salutary for our programs, as well as a good example of the accreditation process at its best--continuous improvement through continuous self-assessment.

LANCE SCHACHTERLE joined WPI as an assistant professor of English in 1970, and served from 1984 to 1993 as chair of Interdisciplinary Studies, overseeing WPI's unique Interactive Qualifying Project program with its extensive experimentation in global education. Schachterle was appointed an Assistant Provost in 1993, and co-chairs the committee preparing WPI for ABET review under the new "Engineering Criteria 2000." 